\title{
The Performance Evaluation and Field Application of Low Temperature Coalbed Gas Clean Fracturing Fluid
}

\author{
Jianhan $\mathrm{Xu}^{1,2}$, Jiao $\mathrm{Ka}^{3}$, Shoucheng Wen ${ }^{1,2^{*}}$, Bin Liu ${ }^{4}$, Jidan Tang ${ }^{4}$ \\ ${ }^{1}$ University of Petroleum Engineering, Yangtze University, Wuhan, China \\ ${ }^{2}$ Collaborative Innovation Center for Unconventional Oil and Gas, Yangtze University, Wuhan, China \\ ${ }^{3}$ China Oilfield Services Ltd. (COSL Drilling Shenzhen), Shenzhen, China \\ ${ }^{4}$ Coalbed Methane Exploration and Development Division, North China Oilfied Company, Changzhi, China \\ Email: *wenshoucheng1234@163.com
}

How to cite this paper: Xu, J.H., Ka, J., Wen, S.C., Liu, B. and Tang, J.D. (2018) The Performance Evaluation and Field Application of Low Temperature Coalbed Gas Clean Fracturing Fluid. Open Journal of Yangtze Gas and Oil, 3, 231-239.

https://doi.org/10.4236/ojogas.2018.34020

Received: September 6, 2017

Accepted: October 23, 2018

Published: October 26, 2018

Copyright $\odot 2018$ by authors and Scientific Research Publishing Inc. This work is licensed under the Creative Commons Attribution International License (CC BY 4.0).

http://creativecommons.org/licenses/by/4.0/

\begin{abstract}
Clean fracturing fluid has many advantages, such as strong sand carrying capacity, strong ability to high generation and low friction, etc. However, the temperature of coalbed gas in the shallow part is low $\left(25^{\circ} \mathrm{C}\right.$ to $\left.35^{\circ} \mathrm{C}\right)$. And there are no liquid hydrocarbons or no large amount of free water in the reservoir, which can make fracturing fluid break. The difficulty to break the clean fracturing fluid could result in serious reservoir damage during fracturing. This paper introduces many breakers for cleaning fracturing fluid. And the performances of those breakers have been evaluated in the condition of low temperature. On the base of research, the breaker for clean fracturing fluid is recommended for coalbed gas in the shallow part. The breaker can break clean fracturing fluid completely in low temperature of $25^{\circ} \mathrm{C}$. At the same time, the degree of damage caused by fracturing fluid is evaluated. The damage rate of fracturing fluid is only $11 \%$. The system of cleaning fracturing fluid has been applied in Qinshui Basin of Shanxi Province. The field experiment has achieved good results.
\end{abstract}

\section{Keywords}

Viscoelastic Surfactant (VES) Fracturing Fluids, Coalbed Methane, Gel Breaking Agent, Residue of Fracturing Fluid Breaking

\section{Introduction}

Fracturing is an important measure to improve the productivity of unconventional reservoirs such as coalbed methane and shale gas. Fracturing fluid performance is directly related to the transformation of oil and gas wells. At 
present, there are three kinds of fracturing fluids being applied in the field, such as active water fracturing fluid, polymer fracturing fluid and viscoelastic surfactant fracturing fluid. Active water fracturing fluid has many problems, such as high frictional resistance and sands displacement, which affect the overall effect of fracturing [1]. Compared with the active water, the polymer fracturing has strong sand carrying capacity, low filtration and strong sewing ability, and so on. However, the polymer fracturing fluid can't be broken in the condition of low temperature (bellow $25^{\circ} \mathrm{C}$ ). And it makes the polymer fluid difficult to flow back. On the other hand, the polymer fluid would be adsorbed or trapped in the reservoir pores. They could cause serious formation damage [2]. Clean fracturing fluid is the kind of solution based on viscoelastic surfactant, which has strong shear resistance and good sand carrying capacity. The fracturing fluid contains no solid after gel breaking and has low friction. Therefore, the clean fracturing fluid has a wide application prospect in coalbed gas in the shallow part [3].

Viscoelastic surfactant molecule contains hydrophilic groups and hydrophobic groups, which show positive and negative charges. Before the surfactant concentration reaches the critical micelle concentration, the molecules of surfactant are present in a single group or small groups. However, the surfactant molecules spontaneously form spherical micelles with low viscosity when the concentration reaches the critical micelle concentration because the hydrophobic group repels the aqueous phase and the hydrophilic group extends into the aqueous phase. The repulsive force between the cationic groups of the surfactant is reduced by electrostatic attraction of the counterion, electrostatic attraction of the discharge aiding agent and electrostatic attraction between the surfactants. As a result, the aggregation form of the viscoelastic surfactant is transformed from spherical glued gels to worm-like glued gels. The worm-like micelles are a three-dimensional network structure, which makes the gels with high viscoelastic. The properties help the clean fracturing fluid to get strong capacities of wide generation and carry proppants [4] [5]. The breaking mechanism of clean fracturing fluid is as follows: The polar material is absorbed on the worm-like micellar network structure, which leads to the reduce of the network structure relaxation time by 3 to $4 \mathrm{nn}$ e other hand, some part chains of the polymer wraps around the surface of the micelle. And the other part chains of the polymer point to the aqueous phase. The surfactant micelles are separated. As a result, the formation of worm-like micelles is prevented, which makes the solution lose its viscoelasticity [6]. The breaking should be carried out after the completion of the strata stage. And the fracturing fluid must be broken thoroughly as soon as possible to reduce the damage to the reservoir. Figure 1 shows the cleaning of fracturing fluid into glue and breaking glue.

In the process of fracturing operation in low-temperature conditions, the rheology of fracturing fluid, shear resistance, and suspended sand properties are easy to realize. In order to apply the clean fracturing fluid in coalbed gas in shallow part, the key issue is to solve fracturing fluid break in the condition of 


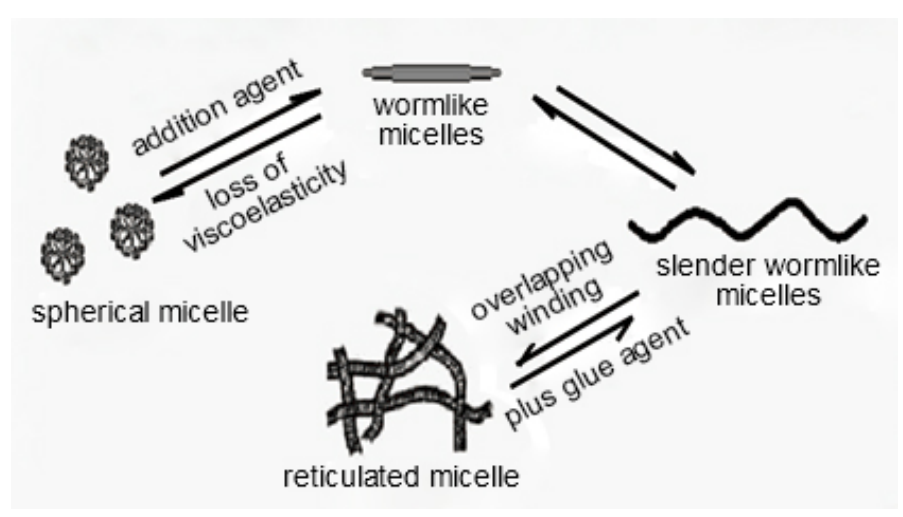

Figure 1. Gel and gel breaking.

low temperature [7]. So it is particularly important to screen the gel breaker, which would contribute to control the gel broken time and reduce the damage of fracturing fluid on the underlying layer [8] [9]. In this paper, the concept of recessive breaker is introduced in the system, so that the fracturing fluid is completely broken when the $\mathrm{CBM}$ reservoir temperature is below $35^{\circ} \mathrm{C}$, which solves the problem that the clean fracturing fluid cannot be broken in the fracturing process because of lack of free water or liquid hydrocarbon, especially under the low temperature in coalbed gas in the shallow part. The fracturing fluid filtrate has less damage to the reservoir. This system can be used for the CBM reservoir in the shallow part fracturing.

\section{Lab Testing and Discussions}

\subsection{Experiment and Discussion of VES Gel Breaker}

\subsubsection{Rheological Property Test}

A six-speed rotary viscometer is used for testing the viscosity in the laboratory: first of all, take $500 \mathrm{~mL}$ clean fracturing fluid products $(0.4 \% \mathrm{VES}+0.15 \% \mathrm{SSN}+$ $1.0 \%$ clay swelling inhibitor $+0.06 \%$ synergist $+0.08 \%$ residue inhibitor); secondly, select different quantities of gel breakers, and add the gel breakers into the product A respectively; finally, record the viscosity values in the conditions of $100 \mathrm{r} / \mathrm{min}$ and $25^{\circ} \mathrm{C}$.

Figure 2 indicates that the self-made gel breaker cannot break clean fracturing

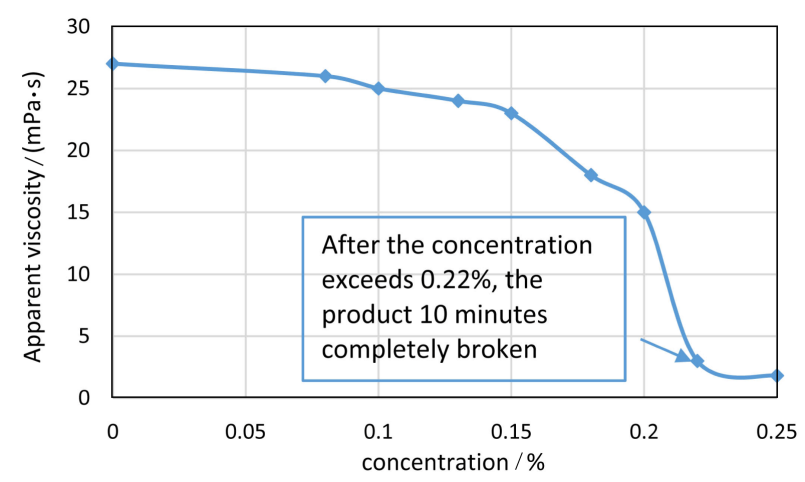

Figure 2. Experimental plot of nonionic surfactants. 
fluid gel completely after 15 hours when the dosage of non-ionic surfactants is less than $0.220 \%$. However, if the dosage of non-ionic surfactants is more than $0.220 \%$, the self-made gel breaker can break the clean fracturing fluid gel completely in 10 minutes at a low temperature. And the broken solution is clear and free of residues, but the gel break downtime is too short to guarantee sand carrying.

Figure 3 indicates that the sand carrying capacity is lost 2 - 3 hours after the addition of self-made gel breaker. And the fracturing fluid is broken after 12 hours when the dosage is about $0.045 \%-0.055 \%$. Therefore, the self-made gel breaker can break the fracturing fluid gel at a low temperature condition. However, there is a large amount of oil released from the fracturing fluid, which would result in heavy formation damage. In order to solve the problem, the non-ionic surfactant and recessive gel breaker are compounded.

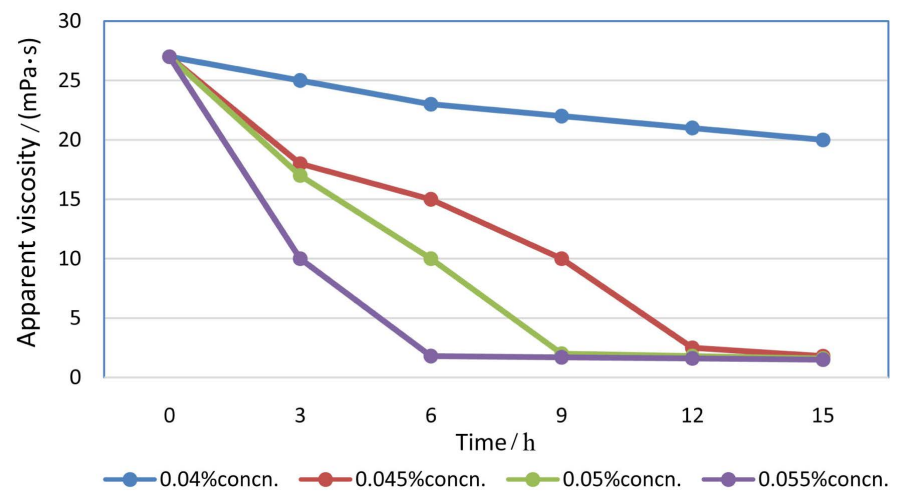

Figure 3. Experimental data of self-made breaker.

Figure 4 indicates that the sand carrying capacity is lost 1.5 to 3 hours after the addition of $0.035 \%-0.040 \%$ of the self-made gel breaker and $0.335 \%$ $0.450 \%$ of non-ionic surfactants. And after 6 to 8 hours, the fracturing fluid is broken completely. Figure 5 shows that no oil phases are released on the surface of the broken solution.

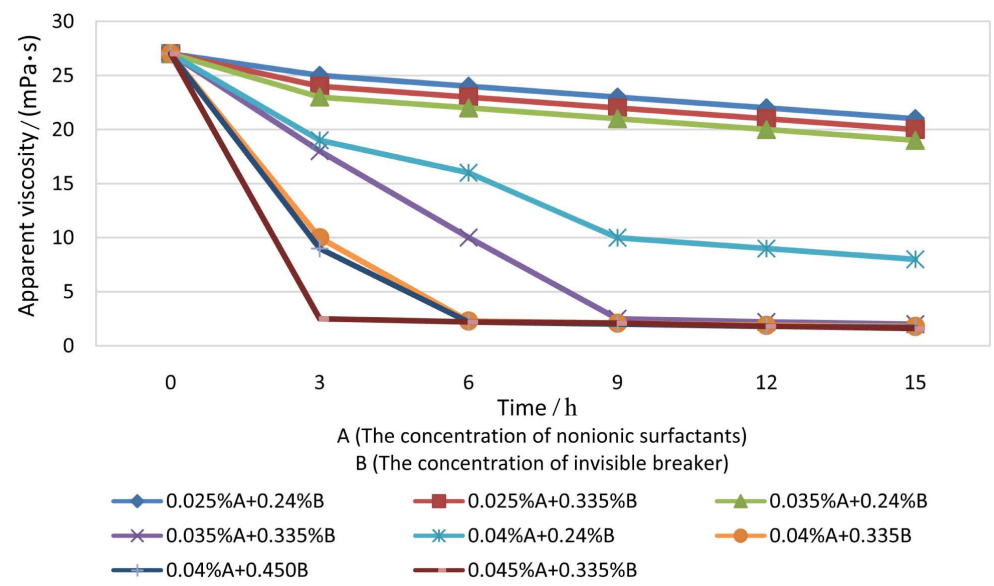

Figure 4. Experimental data of complex breaker. 


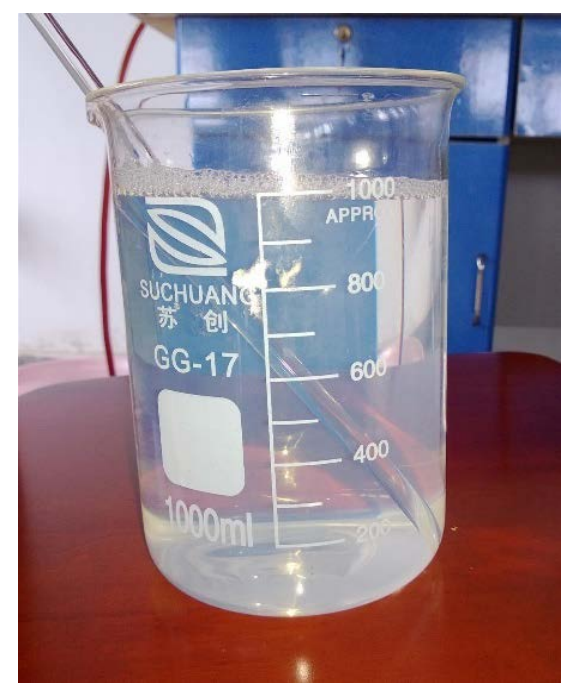

Figure 5. Picture after breaking.

\subsubsection{Capillary Viscosimeter}

Because the six-speed rotary viscometer is not sensitive to low viscosity fluid, the coriolisviscosity meter is utilized to measure the viscosity of the obtained gel broken solution [10]. After a six-speed rotary viscometer test is completed, $10 \mathrm{~mL}$ of the solution is taken with a pipette, and put into the coriolisviscosity meter. And the coriolisviscosity meter is put into a temperature-controlled water bath at a set temperature of $25^{\circ} \mathrm{C}$. Compared with the water-based retention time, the relative viscosity was obtained by using an equation to calculate the retention time for a whole night.

In Figure 6, the relative viscosity of the self-made clean fracturing fluid is showed after being heated for 15 hours at a constant temperature of $25^{\circ} \mathrm{C}$ after the addition of the optimum concentration of the combination breakers. Figure 6 shows the formulations of all breakers used in the test. The viscosity of clean fracturing fluid is between $1.2 \mathrm{mPa} \cdot \mathrm{s}$ to $1.4 \mathrm{mPa} \cdot \mathrm{s}$ after breaking. Data indicates that there exists an optimal ratio between the recessive breaker and nonionic surfactant. The breaker cannot break the fracturing fluid completely beyond the optimization ratio.

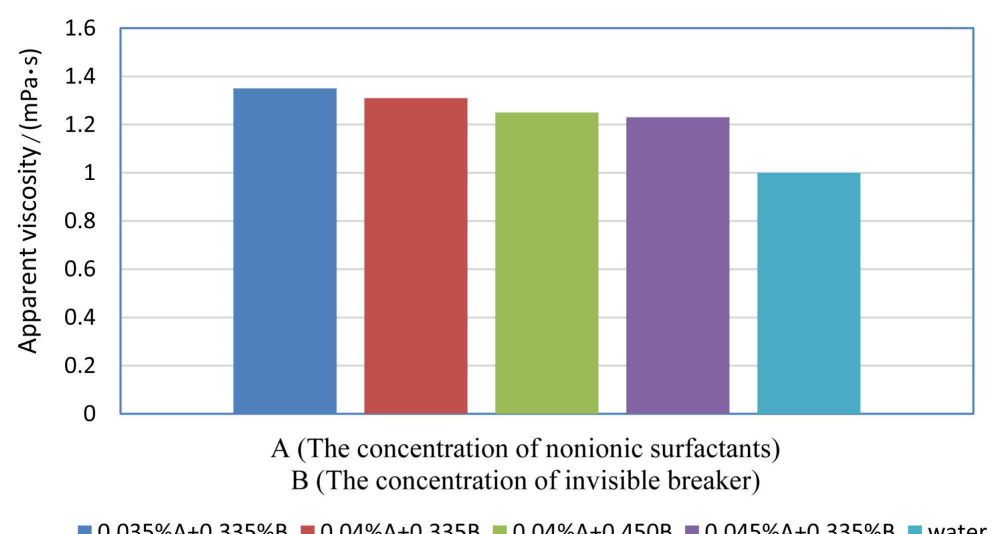

Figure 6. The viscosity of the complex breaker. 


\subsection{Formation Damage Assessment}

Core displacement test is carried out to evaluate the damage of the gel broken solution of the product A. The displacement core is made by coal powders, which pass through 100 mesh screen. A metal cylinder as cores model is filled by the coal powders and is compacted by $5 \mathrm{MPa}$ pressure for 6 hours. The diameter of the metal cylinder is $5 \mathrm{~mm}$. Both ends of the metal cylinder are mixed by screen after the coal powder is filled in order to prevent the coal powders collapse and outflow during displacement.

After making the core, it is saturated by simulating the coalbed water for 24 hours, and then put into a core holder. The original permeability is measured with simulating formation water. The simulating formation water is injected into the core forward until the quantity of flow and pressure are stable for more than 60 minutes [11]. According to Darcy formula, the original permeability value is obtained by the experiment. Then the clean fracturing fluid is injected into the core reversely for 36 minutes at $25^{\circ} \mathrm{C}$ degree. And the displacement fracturing pressure is stable at 3.5 MPa. The filtrate loss of fracturing fluid is measured under simulated formation pressure and shear rate during fracturing. So, the loss rate of the fracturing fluid is obtained. After the fracturing fluid is injected, the valves on both ends of the holder are closed in order to keep the fracturing fluid stating in the core for 2 hours. Finally, the core is displaced by the formation water reversely. The permeability value is calculated by the experiment. Compared with the original permeability, the damage rate of the permeability is obtained [12].

The study aims to understand the compatibility between the gel broken solution and the coal rocks, but also the compatibility between the gel breaking solution and the coalbed fluid. Therefore, the influence of other factors on the permeability determination should be minimized in the experiment. It is shown that the damage of the gel broken solution to the rock core is relatively smaller in Table 1. It indicates that there is good compatibility between the gel broken solution, core and formation water.

Table 1. Measurement data of fracturing fluid filtrate damage on coal core.

\begin{tabular}{cccccc}
\hline $\begin{array}{c}\text { Core } \\
\text { number }\end{array}$ & $\begin{array}{c}\text { Core } \\
\text { type }\end{array}$ & $\begin{array}{c}\text { Initial } \\
\text { permeability } / 10^{-3} \mu \mathrm{m}^{2}\end{array}$ & $\begin{array}{c}\text { Injection rate of } \\
\text { fracturing fluid } /\left(\mathrm{mL} \cdot \mathrm{min}^{-1}\right)\end{array}$ & $\begin{array}{c}\text { Filtration } \\
\text { time/min }\end{array}$ & $\begin{array}{c}\text { Damage } \\
\text { rate/\% }\end{array}$ \\
\hline S4-520 & Fill san & 30.258 & 0.10 & 120 & 11.5 \\
S1-519 & Fill san & 13.266 & 0.10 & 120 & 15.5 \\
\hline
\end{tabular}

\section{Field Application}

The clean fracturing fluid is applied in well B in Qinshui Basin of Shanxi Province, China. According to well logging interpretation results, the effective porosity of the reservoir is only $4.1 \%$, which indicates that Permeation capacity of the reservoir is poor. The depth of the reservoir is from $731.00 \mathrm{~m}$ to $737.00 \mathrm{~m}$ with a thickness of $6.0 \mathrm{~m}$. Through fracture, cleat cracks are connected. So, the artificial fracture can reach more than 100 meters long. And the conductivity of coalbed 
can be improved greatly. For fracturing design, the total amount of fracturing fluid is $390 \mathrm{~m}^{3}$, including $60 \mathrm{~m}^{3}$ ahead liquid, $300 \mathrm{~m}^{3}$ sand carrying liquid and 30 $\mathrm{m}^{3}$ displacement liquid. Fifteen cubic meters of 40/70 mesh quartz sand, twenty cubic meters of 20/40 mesh quartz sand and ten cubic meters of 16/20 mesh quartz sand are selected as propping agent. When fracturing, the actual amount of fracturing fluid is only 381 cubic meters.

Figure 7 shows that the formation breakdown pressure reaches up to 34.38 $\mathrm{MPa}$. And the closed pressure is $22.53 \mathrm{MPa}$. During fracturing, the construction pressure is stable between $15.06 \mathrm{MPa}$ and $34.38 \mathrm{MPa}$ when the displacement velocity is between $3.0 \mathrm{~m}^{3} / \mathrm{min}$ to $6.0 \mathrm{~m}^{3} / \mathrm{min}$. The ratio of the average sand carrying by fracturing fluid is $17 \%$. After fracturing fluid breaking, the viscosity of the flow back liquid is only $1.09 \mathrm{mPa}$.s. These data show that the construction meets the designed requirements.

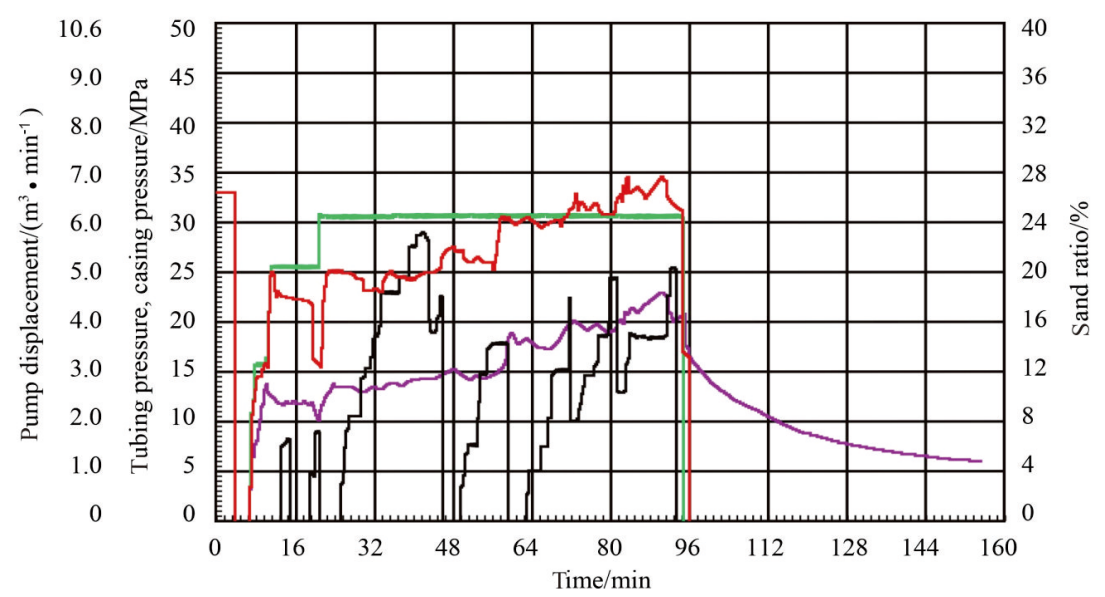

Figure 7. On-site construction curves.

Figure 8 shows the comparison of flied fracturing effects of the self-made clean fracturing fluid and active water fracturing fluid. The production of the well, which is stimulated by the self-made clean fracturing fluid, is twice as much as that of the well stimulated by active water fracturing fluid.

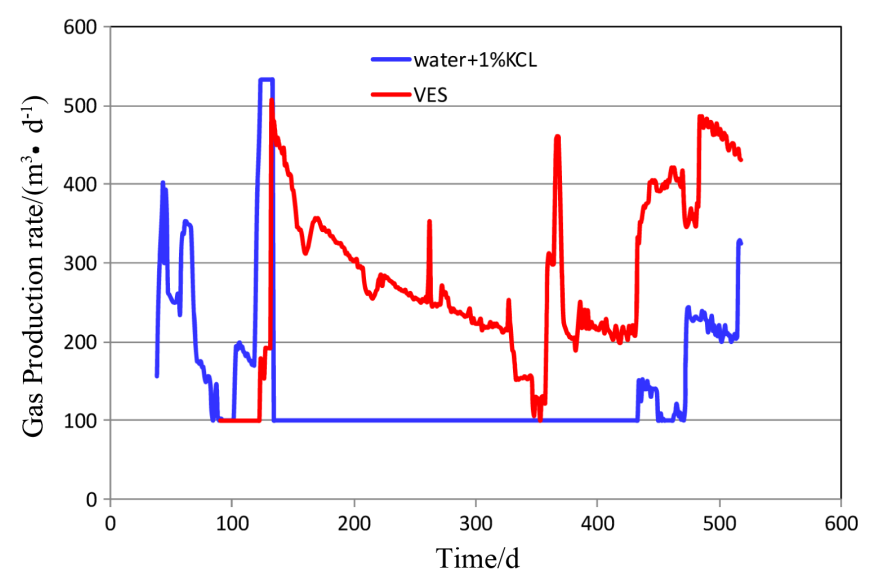

Figure 8. Comparison of daily gas production of two kinds of fracturing fluid. 


\section{Conclusion}

The laboratory data confirm that the mixture of $0.035 \%-0.040 \%$ recessive breaker and $0.335 \%-0.450 \%$ nonionic surfactant could be used as breaker for the clean fracturing fluid. According to the test results of viscometer and capillary tube, the viscosity of clean fracturing fluid after breaking is almost the same as the viscosity of water at low temperature $\left(25^{\circ} \mathrm{C}\right)$. The gel break not only has the advantage of controlling the time of gel break, but also ensures the gel break thoroughly. On the other hand, the results of the core displacement test shows that there is good compatibility between the gel broken solution, the core and the formation water. The results of field application in Qinshui Basin of Shanxi Province show that the production of the well, which is stimulated by the self-made clean fracturing fluid, is twice as much as that of the well, which is stimulated by the active water fracturing fluid. Therefore, the clean fracturing fluid has a wide application prospect in the coalbed gas in the shallow part.

\section{Conflicts of Interest}

The authors declare no conflicts of interest regarding the publication of this paper.

\section{References}

[1] Bao, S.G., Liu, Y.T., Liu, P., et al. (2016) Research Present Situation and Development of Coal-Bed Gas Fracturing Fluid. Coal Science and Technology, 44, 11-17.

[2] Sun, M.Y. and Huang, C. (1997) Overseas Investigation Report on Coalbed Methane Technology. China's Coal, No. 3, 44-46.

[3] Tao, T., Lin, X., Fang, X.X., et al. (2011) Study on the Fracturing Damage Mechanism and Low Damage Fracturing Fluid for CBM Well. Journal of Chongqing University of Science and Technology (Natural Sciences Edition), 13, 21-23.

[4] Liu, X.Q., Yi, M.X., Zhao, J.Y., et al. (2001) Viscoelastic Surfactant Based Fracturing Fluids. Oilflied Chemistry, 18, 273-277.

[5] Wen, S.C., Zhou, M., Wang, W.Y., et al. (2014) Development of Coalbed Methane in Low Temperature Clean Fracturing Fluid and Its Performance Evaluation. Drilling Fluid and Completion Fluid, 31, 79-81.

[6] Zhou, F.J., Lian, Y.F., Yang, X.Y., et al. (2005) Development and Application of High Density Viscoelastic Surfactant Fracturing Fluids. Oil Field Chemistry, 22, 136-139.

[7] Rimmer, B. Fracture Geometry Optimization: Designs Utilizing New Polymer-Free Fracturing Fluid and Log-Derived Stress Profile/Rock Properties. SPE 58761.

[8] Chen, H., Wang, B.H., Zhang, Q.S., et al. (2009) Study and Analysis on Viscoelastic Surfactant Fracturing Fluids. Chemical Industry and Engineering, 26, 361-365.

[9] Zhang, C.J., He, X.G., Guan, X.H., et al. (2009) Low Temperature Clean Fracturing Fluid and Application Prospect in China. Drilling and Production Technology, 32, 93-96.

[10] Liang, Z.Z., Yang, Z.Z., Li, X.G., et al. (2012) Discussion on the Loss of Coalbed Methane Fracturing. Inner Mongolia Petrochemical Industry, No. 13, 33-35.

[11] Yan, Z.H., Dai, C.L., Zhao, M.W., et al. (2015) Study and Application of Clean 
Fracturing Fluid. Oilfield Chemistry, 32, 141-145.

[12] Chen, S.B., Zhu, Y.M., Liu, T.Y., et al. (2009) Effects of Cleaning Fracturing Fluid on Adsorption Performance of Coalbed Methane. Journal of Coal Science, No. 1, 89-94. 